\title{
Avaliação de locais potenciais para instalação de torres de observação para prevenção de risco de incêndios florestais
}

\author{
Assessment of potential sites for the installation of observation towers for forest \\ fire risk prevention
}

\section{Pedro Augusto Gonzaga Moreira ${ }^{\mathrm{I}}$, Thiago Augusto Mendes ${ }^{\mathrm{II}}$, Diego Fonseca dos Santos ${ }^{\mathrm{III}}$}

\begin{abstract}
Resumo
A grande incidência de incêndios florestais observados em Unidades de Conservação faz com que esse evento se torne uma ameaça à proteção dessas áreas. Este artigo apresenta o mapeamento de áreas suscetíveis a incêndios florestais, bem como a identificação de locais potenciais para instalação de torres de vigilância de incêndios florestais para os parques Estaduais Altamiro de Moura Pacheco e João Leite e área de entorno de $3,0 \mathrm{~km}$ de extensão a partir dos limites dos parques, utilizando ferramentas SIG livres. O mapa final de risco de incêndios foi obtido através da sobreposição ponderada dos principais fatores relacionados com incêndios florestais, como: declividade, hipsometria, orientação das encostas, malha viária e trilhas, perímetro urbano, uso do solo, temperatura, umidade e exposição aos ventos. Para determinação de locais potenciais para implantação de torres de observação de incêndios foram considerados os seguintes fatores: relevo (cotas de maior altitude), proximidade das estradas, proximidade com as regiões classificadas com risco moderado e alto e uso do solo. Os resultados mostraram que 9.724,66 ha $(41,4 \%)$ das áreas dos parques avaliados possuem alto risco de incêndios. O mapa de risco de incêndios foi validado considerando os focos de calor disponibilizados pelo INPE (2017), obtendo mais de $60 \%$ de precisão em relação às áreas de risco alto. Com relação aos locais indicados para instalação das torres de observação de incêndios, a instalação apenas de uma torre proporcionou a maior visualização das áreas de estudo, 56,1\%. Combinando a instalação de duas torres, foi possível obter cobertura de visualização de $71,1 \%$ de toda as áreas de estudo. Dessa forma, demostrou-se que a gestão e tomada de decisões ambientais referente ao monitoramento de riscos de incêndios florestais em regiões protegidas podem ser mais bemsucedidas quando complementadas com ferramentas de geotecnologias.
\end{abstract}

Palavras-chave: Parque; Cerrado; SIG; Análise multicritério

\footnotetext{
Engenheiro Ambiental, Mestrando do Programa de Pós-Graduação em Engenharia Ambiental e Sanitária, Universidade Federal de Goiás, Escola de Engenharia, Av. Universitária, Setor Leste Universitário, CEP 74605-220, Goiânia (GO), Brasil. pedrogonzaga94@gmail.com (ORCID: 0000-00029487-6040)

II Engenheiro Civil, Dr., Professor do Instituto Federal de Educação, Ciência e Tecnologia de Goiás, Av. Universitária Vereador Vagner da Silva Ferreira, QD 1, LT 1-A, Parque Itatiaia, CEP 74968-755, Aparecida de Goiânia (GO); Pontifícia Universidade Católica de Goiás, Av. Universitária, 1440, Setor Universitário, Goiânia (GO), Brasil. thiago.mendes@ifg.edu.br (ORCID: 0000-0001-6910-5722)

III Engenheiro Ambiental, Pesquisador Autônomo, Av. Indianápolis, Quadra 119, Lote 13, Bairro Cardoso I, CEP 74933-090, Aparecida de Goiânia (GO), Brasil. diegofonseca.fs@gmail.com. (ORCID: 0000-0003-2224-9360)
} 


\begin{abstract}
The high incidence of forest fires observed in Conservation Units makes this event a threat to the environmental protection of these areas. This article presents the mapping of areas susceptible to forest fires and the identification of potential locations for the installation of forest fire watchtowers for the Altamiro de Moura Pacheco and João Leite State parks and surrounding area, $3.0 \mathrm{~km}$ from the parks' boundaries, using free GIS tools. The final fire risk map was obtained through the weighted average of the main factors related to forest fires, such as: slope angle, hypsometry, orientation of the slopes, road system and trails, urban perimeter, land use, temperature, humidity and exposure to winds. For the determination of potential locations for fire observation towers, the following factors were considered: relief (higher elevations), proximity of roads, proximity to regions classified as moderate and high risk, and land use. The results showed that 9,724.66 ha (41.4\%) of the evaluated parks areas have high fire risk. The fire risk map was validated considering the hotspots made available by INPE (2017), obtaining more than $60 \%$ accuracy in relation to high risk areas. Regarding the locations indicated for the installation of fire observation towers, the installation of only one tower provided the largest view of the study areas, $56.1 \%$. By combining the installation of two towers, it was possible to obtain $71.1 \%$ visualization coverage of the entire studied areas. Thus, it was shown that environmental management and decision-making regarding the monitoring of forest fire risks in protected regions can be more successful when complemented with geotechnology tools.
\end{abstract}

Keywords: Park; Cerrado; GIS; Multicriteria analysis

\title{
Introdução
}

Diante da grande incidência de incêndios florestais em Unidades de Conservação (UCs) no Brasil, a ocorrência de incêndios tem sido vista como um dos principais problemas enfrentados pelos gestores dessas áreas e pode ser considerada grave ameaça para a conservação da biodiversidade e da manutenção de processos ecológicos (PRUDENTE, 2010; ALMEIDA et al., 2018).

Com relação ao Cerrado, o fogo pode ser considerado como um evento natural ou parte da dinâmica do bioma, prova disso são os registros de ocorrência de fogo no Cerrado anteriores à ocupação humana (MIRANDA et al., 2002; PEREIRA JUNIOR, 2002; FERREIRA et al., 2019). A Secretaria de Estado de Meio Ambiente e Desenvolvimento Sustentável de Goiás (SEMAD) aponta que a discussão sobre a utilização e o manejo do fogo no Cerrado ainda não chegou a resultados conclusivos, uma vez que o fogo hoje em dia ocorre com frequência muito maior e as áreas naturais são cada vez menores, o que pode ter aumentado o impacto de incêndios frequentes (ITCO, 2007).

Assim, torna-se necessário o monitoramento dessas áreas e o mapeamento do risco de incêndios, possibilitando ações de combate mais rápidas e eficientes. Em relação a isso, uma questão relevante é a determinação de zonas com maior risco de incêndio, tendo como principal função o auxílio no planejamento de combate (VADREVU et al., 2009; TORRES et al., 2018; FERREIRA et al., 2019).

O risco de incêndios pode ser abordado por meio de mapeamento, identificando as regiões com maiores ou menores riscos de incêndios em uma área florestal (FERRAZ; VETTORAZZI, 1998; PRUDENTE, 2010; TAVARES et al., 2019). Para o mapeamento podem ser utilizados fatores inerentes à área de estudos, como cobertura vegetal, relevo (declividade, hipsometria, orientação das encostas) e proximidade das vias e trilhas (CHUVIECO; CONGALTON, 1989).

Diante disso, Prudente (2010) aponta que os mapas de risco de incêndio florestais são resultados da representação das áreas mais suscetíveis ao fogo em um mapa base, gerado através da integração dos fatores que influenciam na ignição ou na propagação do fogo. Por meio dessas informações oferecidas pelo mapa de risco, várias medidas podem ser tomadas, como: maior vigilância nas áreas de risco, restrição de acesso, construção de aceiros preventivos e reorganização das práticas de manejo (FERRAZ; VETTORAZZI, 1998). 
Nesse contexto, a utilização de torres de observação constitui um método de detecção de focos de incêndio, oferecendo subsídios importantes para diminuir o tempo do primeiro combate, tendo em vista que a construção de torres em pontos estratégicos permite abrangência de visibilidade do observador na identificação dos focos de incêndio (VENTURI, 2006). Nogueira et al. (2002) apontam que os critérios geralmente utilizados para escolha dos locais para instalação das torres são: relevo, vias de acesso, altitude dos pontos, formação vegetal, visibilidade e importância da área a ser protegida.

Sendo assim, pode-se destacar a viabilidade de se utilizar sistemas de informações geográficas (SIGs) como ferramenta de diagnóstico, prevenção e tomada de decisões, tanto para o mapeamento de risco de incêndios florestais (CHUVIECO; CONGALTON, 1989; FERRAZ; VETTORAZZI, 1998; VADREVU et al., 2009; PRUDENTE, 2010) quanto para a escolha de locais potenciais para instalação de torres de observação (NOGUEIRA et al., 2002; VENTURI, 2006; ASSIS et al., 2014; EUGENIO et al., 2016).

Dessa forma, este artigo tem como objetivo realizar mapeamento de áreas de risco de incêndios florestais no parque Estadual Altamiro de Moura Pacheco (PEAMP), parque Estadual João Leite (PEJoL) e área de entorno, bem como definir quantidade e locais potenciais para instalação de torres de vigilância de incêndios florestais paras as áreas de estudo utilizando ferramentas SIG livres.

\section{Materiais e métodos}

As Unidades de Conservação (UCs), ou seja, as áreas de estudo consideradas foram: parque Estadual Altamiro de Moura Pacheco (PEAMP), parque Estadual João Leite (PEJoL) e área de entorno (3,0 $\mathrm{km}$ de extensão a partir do limite dos parques), conforme proposto pela resolução CONAMA 428/2010 (BRASIL, 2010) (Figura 1).

\section{Figura 1 - Localização do PEAMP, PEJoL e área de entorno}

Figure 1 - Location of PEAMP, PEJoL and surrounding area

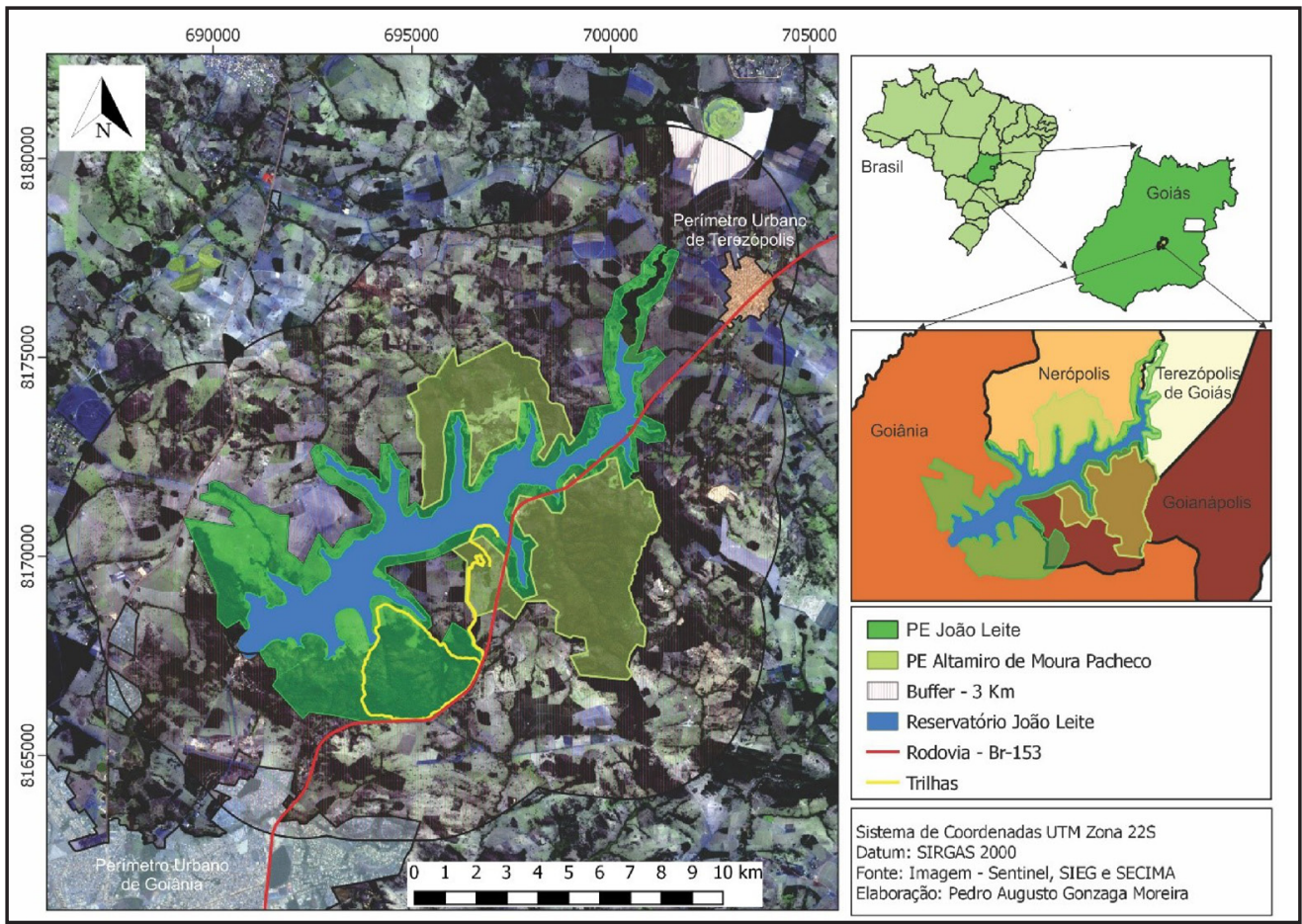

Fonte: Autores (2019) 
As UCs estão localizadas nos municípios de Goiânia, Goianápolis, Nerópolis e Terezópolis de Goiás - GO, inseridas na área de preservação permanente João Leite, onde o PEAMP possui área de 2.132 ha, composto por duas áreas descontínuas, e o PEJoL, apresentando área de 2.832 ha.

O PEAMP e o PEJoL foram selecionados por serem UCs de importância estratégica, sendo que o PEAMP protege o maior remanescente de Mata Seca da região central do Estado de Goiás, bem como sítios arqueológicos que abrigam vestígios da presença de povos indígenas. Já o PEJoL visa preservar a qualidade da água do reservatório de captação para abastecimento público da região metropolitana e Goiânia, assim como controlar a ocupação do solo da região e também os constantes incêndios florestais.

Em 1998, ano do maior incêndio registrado, o fogo consumiu praticamente $90 \%$ da totalidade da vegetação dos parques (ITCO, 2007). Com isso, a partir do ano de 2002, iniciouse a implantação e a manutenção de medidas preventivas (aceiros) que auxiliam no combate a incêndios, minimizando a ação dos focos de incêndio florestal no PEAMP, mas ainda sendo insuficientes (ITCO, 2007), o que evidencia a necessidade de outras formas de gestão (mapa de risco de incêndios) e controle (torres de observação de incêndios).

Dessa forma, três principais etapas metodológicas foram desenvolvidas e aplicadas (Figura 2). Inicialmente, buscou-se identificar em publicações acadêmicas as principais variáveis que influenciam o risco de incêndios florestais, para assim criar o banco de dados geográficos e climáticos necessários para a elaboração da base cartográfica das áreas de estudos (Etapa 1).

Figura 2 - Fluxograma metodológico geral

Figure 2 - General methodological flowchart

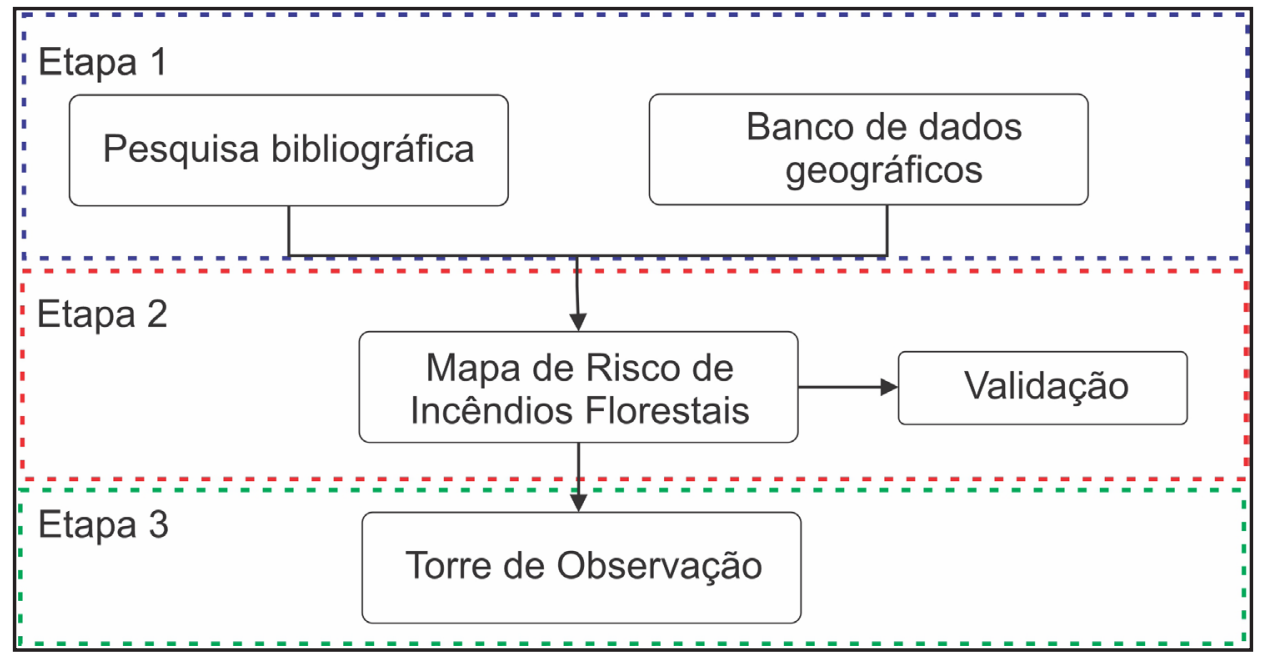

Fonte: Autores (2019)

A base cartográfica das áreas de estudo (dados geográficos), necessária para a execução das etapas 2 e 3 (Figura 2), foi obtida do Sistema de Informação Geográfica de Goiás (SIEG) (limites dos parques estaduais e área de entorno, limites municipais, perímetros urbanos, rede de drenagem e malha viária); da Secretária de Estado de Meio Ambiente e Desenvolvimento Sustentável de Goiás (SEMAD) (trilhas), Instituto Nacional de Pesquisas Espaciais (INPE) (modelo digital de elevação e focos de incêndios); imagem Sentinel 2 disponibilizada pela ESA (European Space Agency) na plataforma landview. Os dados climatológicos (temperatura, umidade e direção dos ventos) foram obtidos junto ao Sistema de Meteorologiado Estado de Goiás (SIMEHGO) e Instituto Nacional de Meteorologia (INMET). 


\section{Etapa 1: variáveis envolvidas na elaboração do mapa de risco de incêndios florestais}

A topografia é um dos principais fatores para classificação de risco de incêndios florestais (CHUVIECO; CONGALTON, 1989). Assim, considerou-se alguns aspectos topográficos como: declividade, hipsometria e orientação das encostas. Os mapas referentes a esses elementos foram gerados a partir dos dados do projeto Topodata (INPE), utilizando ferramentas do software Qgis 2.18 (Qgis, 2017).

\section{Declividade do terreno}

A declividade do terreno foi considerada como fator de propagação de incêndios, tendo em vista que áreas mais inclinadas são consideradas de maior suscetibilidade, pois a transferência de calor é facilitada no sentido do aclive, aumentando a velocidade de propagação do incêndio. Um incêndio, quando se propaga em um aclive acentuado, se assemelha a um incêndio se propagando no plano, sob efeito de um forte vento (FERRAZ; VETTORAZZI, 1998; RIBEIRO et al., 2008; PRUDENTE, 2010).

Ribeiro et al. (2008) apontam ainda que o relevo exerce grande influência sobre o clima e, em menor escala, sobre a vegetação e sobre o material combustível das diversas regiões terrestres.

\section{Hipsometria}

A altitude é uma variável que influencia o risco de incêndio devido à sua relação com a umidade relativa do ar. Isso se deve ao fato de que, com o aumento da altitude, observa-se um decréscimo da temperatura e, consequentemente, um valor elevado de umidade relativa do ar. Assim, o mapa hipsométrico representa indiretamente a umidade do material combustível e a redução do risco de incêndio (SALAS; CHUVIECO, 1994).

\section{Orientação das encostas}

A importância da orientação das encostas está relacionada com a disponibilidade energética para a redução da umidade do material combustível (PEZZOPANE et al., 2001). No hemisfério Sul os raios solares incidem mais diretamente sobre faces voltadas para o norte, transmitindo maior quantidade de calor para essa exposição do que para as outras. A face oeste é a segunda a receber maior quantidade de energia, seguida da face leste. A face sul é a que menos recebe radiação (RIBEIRO, 2009).

\section{Malha viária, trilhas e área urbana}

A análise desses parâmetros envolveu a utilização da ferramenta buffer, que cria polígonos em distância específica ao redor de feições selecionadas no software Qgis 2.18 (Qgis, 2017). As distâncias adotadas estão especificadas na Tabela 2, onde são apresentadas todas as variáveis e os parâmetros utilizados na elaboração do mapa de risco de incêndios florestais.

As estradas e trilhas podem ser consideradas como rotas potenciais para o acesso de pessoas, portanto vistas como aspecto preponderante ao risco de incêndio pelos fatores: incêndios criminosos, cultos religiosos praticados no local, incêndios causados por cigarros, pequenas fogueiras construídas na área (FERRAZ; VETTORAZZI, 1998; PRUDENTE, 2010). Em relação às áreas urbanas, destaca-se que o entorno é de alta suscetibilidade a incêndios, pois são áreas de fácil acesso, apresentando grande concentração de pessoas e pouca fiscalização. 


\section{Uso do solo}

Prudente (2010) aponta que o conhecimento do uso da terra e cobertura vegetal é de fundamental importância para análise do risco de incêndio, uma vez que o tipo de cobertura vegetal influencia o comportamento do fogo, pois a variação na cobertura vegetal implica em mudanças de aspectos relacionados com o comportamento do fogo, principalmente combustível e condições climáticas.

A classificação e o mapeamento do uso do solo foram elaborados no software livre Spring 5.02, utilizando-se técnica de classificação supervisionada pelo método da verossimilhança. De forma complementar foi utilizada a classificação de uso e cobertura do solo para o bioma Cerrado (escala 1:250.000) gerada pelo Projeto de Conservação e Utilização Sustentável da Diversidade Biológica Brasileira - PROBIO (2002).

\section{Fatores climatológicos}

A ocorrência, a frequência e a intensidade dos incêndios dependem diretamente do clima (condições climáticas), e permitem a ignição e, indiretamente, o fornecimento de carga de combustível para sustentar o fogo (VADREVU et al., 2009). Neste estudo os fatores climatológicos utilizados foram: temperatura e umidade relativa do ar e face de exposição a ventos, obtidos nas estações meteorológicas indicadas na Tabela 1.

\section{Tabela 1 - Estações climatológicas}

Table 1 - Climatological stations

\begin{tabular}{lccc}
\hline \multicolumn{1}{c}{ Estação } & Longitude & Latitude & Fonte \\
\hline Goiânia Heliponto & $16^{\circ} 37^{\prime} 44.16^{\prime \prime S}$ & $49^{\circ} 12^{\prime} 58.98^{\prime \prime O}$ & SIMEHGO \\
Goiânia Inmet & $16^{\circ} 40^{\prime} 23.73^{\prime \prime} \mathrm{S}$ & $49^{\circ} 15^{\prime} 50.05^{\prime \prime} \mathrm{O}$ & INMET \\
Anápolis & $16^{\circ} 22^{\prime} 52.73^{\prime \prime} \mathrm{S}$ & $48^{\circ} 56^{\prime} 46.34^{\prime \prime} \mathrm{O}$ & SIMEHGO \\
\hline
\end{tabular}

Fonte: Autores (2019)

Para os dados relativos à temperatura e umidade do ar foram consideradas as médias mensais, segundo a série histórica de 2005 a 2016, para as estações localizadas em Anápolis e do INMET em Goiânia, e de 2007 a 2016 para a estação Goiânia Heliponto. Os dados referentes à temperatura e umidade do ar foram tabulados e especializados no software livre Qgis, versão 2.18 (Qgis, 2017) por meio da técnica de interpolação conhecida como Peso pelo Inverso da Distância (SANTOS; CRUZ, 2016), do inglês Invert Distance Weighted (IDW).

Em relação à direção dos ventos, utilizaram-se os dados disponibilizados pela estação Goiânia Heliponto, devido à proximidade com as áreas de estudo. A direção predominante do vento foi caracterizada a partir da composição em rosas dos ventos (PIMENTEL et al., 2014), utilizando-se o software livre WRPLOT 2.5.

As médias mensais da série mostraram que o mês de setembro apresenta a maior temperatura média e o segundo menor índice de umidade. Consequentemente, esse período possui maior potencial à ocorrência de incêndios florestais para as áreas em estudo, levando em consideração apenas os fatores climáticos. Setembro foi, portanto, escolhido para a determinação do mapa de risco de incêndios. 


\section{Temperatura do ar}

A maior suscetibilidade à ocorrência de incêndios florestais é diretamente proporcional à elevação da temperatura do ar, visto que essa condição resulta numa redução da umidade do material (ASSIS et al., 2014).

Silva (1998) aponta ainda que a temperatura do solo também aumenta a corrente de ar que, aquecida pelo sol, seca o material combustível, fazendo com que ele se queime mais facilmente, ou seja, os materiais combustíveis pré-aquecidos pelo sol queimam-se com mais facilidade do que aqueles que estão frios.

\section{Umidade}

Prudente (2010) destaca que a umidade atmosférica é um dos fatores mais importantes na propagação de incêndios florestais, sendo que, em períodos extremamente secos, a baixa umidade pode afetar o conteúdo de umidade do material combustível vivo (VENTURI, 2006).

O material seco absorve umidade da atmosfera úmida e libera água quando o ar está seco. A quantidade de umidade que o material morto pode absorver e reter do ar depende, basicamente, da umidade relativa do ar (BATISTA, 2000).

\section{Direção dos ventos}

Iniciado o fogo, o vento ajuda na propagação, transportando calor e fagulhas e inclinando as chamas para áreas dos incêndios florestais, ativando a combustão através do fornecimento contínuo de oxigênio proveniente do ar atmosférico (VENTURI, 2006). As faces voltadas para leste, oeste, leste nordeste são as que mais diretamente recebem os ventos predominantes na região (Figura 3).

\section{Figura 3 - Distribuição da frequência de ventos}

\section{Figure 3 - Wind frequency distribution}

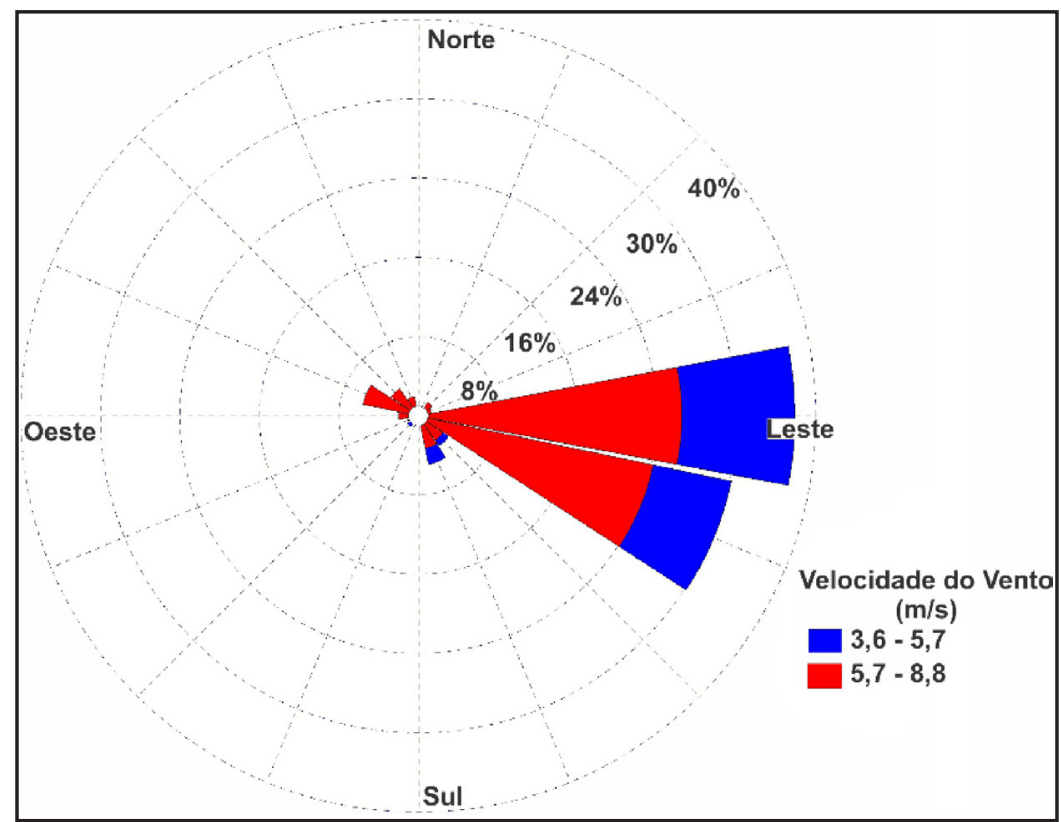

Fonte: WRPLOT View (2018) - adaptado do software 


\section{Etapa 2: Elaboração do mapa de risco de incêndio florestal (MRIF)}

A elaboração do MRIF seguiu as recomendações de Chuvieco e Congalton (1989), Ferraz e Vetorazzi (1998), Prudente (2010), Barbosa et al. (2010), White et al. (2016) e Pereira e Dutra (2017). Para a elaboração do MRIF das áreas de estudo, primeiramente, foram determinadas notas (0 a 3) para cada parâmetro da Tabela 2 , de maneira que quanto maior a nota, maior a influência desse parâmetro no risco de incêndio ( 0 - nula, 1 - baixa, 2 - média, 3 - alta).

O MRIF para as áreas de estudo foi elaborado a partir da técnica de álgebra de mapas temáticos (Figura 4), classificados de acordo com os parâmetros apresentados na Tabela 2.

Tabela 2 - Notas atribuídas aos parâmetros de risco de incêndios florestais

Table 2 - Notes attributed to forest fire risk parameters

\begin{tabular}{|c|c|c|c|}
\hline Parâmetro & Classes & Notas & Suscetibilidade ao fogo \\
\hline \multirow{3}{*}{ Declividade $^{1,2}$} & $0-12 \%$ & 1 & Baixa \\
\hline & $12-40 \%$ & 2 & Média \\
\hline & $>40 \%$ & 3 & Alta \\
\hline \multirow{3}{*}{ Hipsometria $^{3}$} & $>1500 \mathrm{~m}$ & 1 & Baixa \\
\hline & $1200-1500 m$ & 2 & Moderada \\
\hline & $600-1200 m$ & 3 & Alta \\
\hline \multirow{3}{*}{$\begin{array}{l}\text { Orientação das } \\
\text { Encostas }^{1,3}\end{array}$} & Sul, Sudeste, Sudoeste & 1 & Baixa \\
\hline & Leste, Oeste & 2 & Média \\
\hline & Norte, Nordeste, Noroeste & 3 & Alta \\
\hline \multirow{3}{*}{$\begin{array}{l}\text { Malha Viária e } \\
\text { Trilhas }^{5}\end{array}$} & $0-200(\mathrm{~m})$ & 3 & Alta \\
\hline & $200-400(\mathrm{~m})$ & 2 & Média \\
\hline & $>400(\mathrm{~m})$ & 3 & Baixa \\
\hline \multirow{3}{*}{$\begin{array}{l}\text { Perímetro } \\
\text { urbano }^{1}\end{array}$} & $<1000(\mathrm{~m})$ & 3 & Alta \\
\hline & $>1000(\mathrm{~m})$ & 1 & Baixa \\
\hline & Reservatório & 0 & Nula \\
\hline \multirow{3}{*}{ Uso do Solo 6} & Área urbana, rodovias e solo exposto & 1 & Baixa \\
\hline & Vegetação nativa, Floresta Estacional Semidecidual & 2 & Média \\
\hline & Agricultura, pastagem, Floresta Estacional Decidual & 3 & Alta \\
\hline \multirow{3}{*}{ Temperatura $^{3}$} & $<24^{\circ} \mathrm{C}$ & 1 & Baixa \\
\hline & $24-26^{\circ} \mathrm{C}$ & 2 & Média \\
\hline & $>26^{\circ} \mathrm{C}$ & 3 & Alta \\
\hline \multirow{3}{*}{ Umidade $^{4}$} & $>70$ & 1 & Baixa \\
\hline & $45-70$ & 2 & Média \\
\hline & $<45$ & 3 & Alta \\
\hline \multirow{3}{*}{$\begin{array}{l}\text { Exposição a } \\
\text { Ventos }^{2}\end{array}$} & Demais direções & 1 & Baixa \\
\hline & Lés Sudeste & 2 & Média \\
\hline & Leste, Oeste, Sul, Lés Nordeste & 3 & Alta \\
\hline
\end{tabular}

Fonte: Chuvieco e Congalton (1989) ${ }^{1}$; Ferraz e Vettorazzi (1998) ${ }^{2}$; Prudente (2010) ${ }^{3}$; Barbosa (2010)4; Pereira e Dutra $(2017)^{5}$ e White et al. $(2016)^{6}$ 
Essa superposição foi realizada a partir de adaptação do modelo proposto por Prudente (2010), agora acrescido da variável direção do vento, que indica o quanto cada variável tem influência na ocorrência de um incêndio florestal Equação (1):

$$
\begin{aligned}
\text { Risco } & =30{ }^{*} U S O+20{ }^{*} \text { DEAU }+15^{*} \mathrm{OE}+10{ }^{*} \mathrm{DEC}+ \\
& +10{ }^{*} \mathrm{HIPSO}+5{ }^{*} \mathrm{~V}+5{ }^{*} U+5{ }^{*} \mathrm{~T}
\end{aligned}
$$

onde: $U S O$ = uso do solo; $D E C$ = declividade; $D E A U$ = distância da malha viária, trilhas e área urbana; $T$ = temperatura do ar; $U$ = umidade; $V=$ ventos; $O E=$ orientação das encostas; $H I P S O=$ hipsometria.

\section{Figura 4 - Fluxograma para elaboração e avaliação do MRIF}

Figure 4 - Flowchart for MRIF elaboration and evaluation

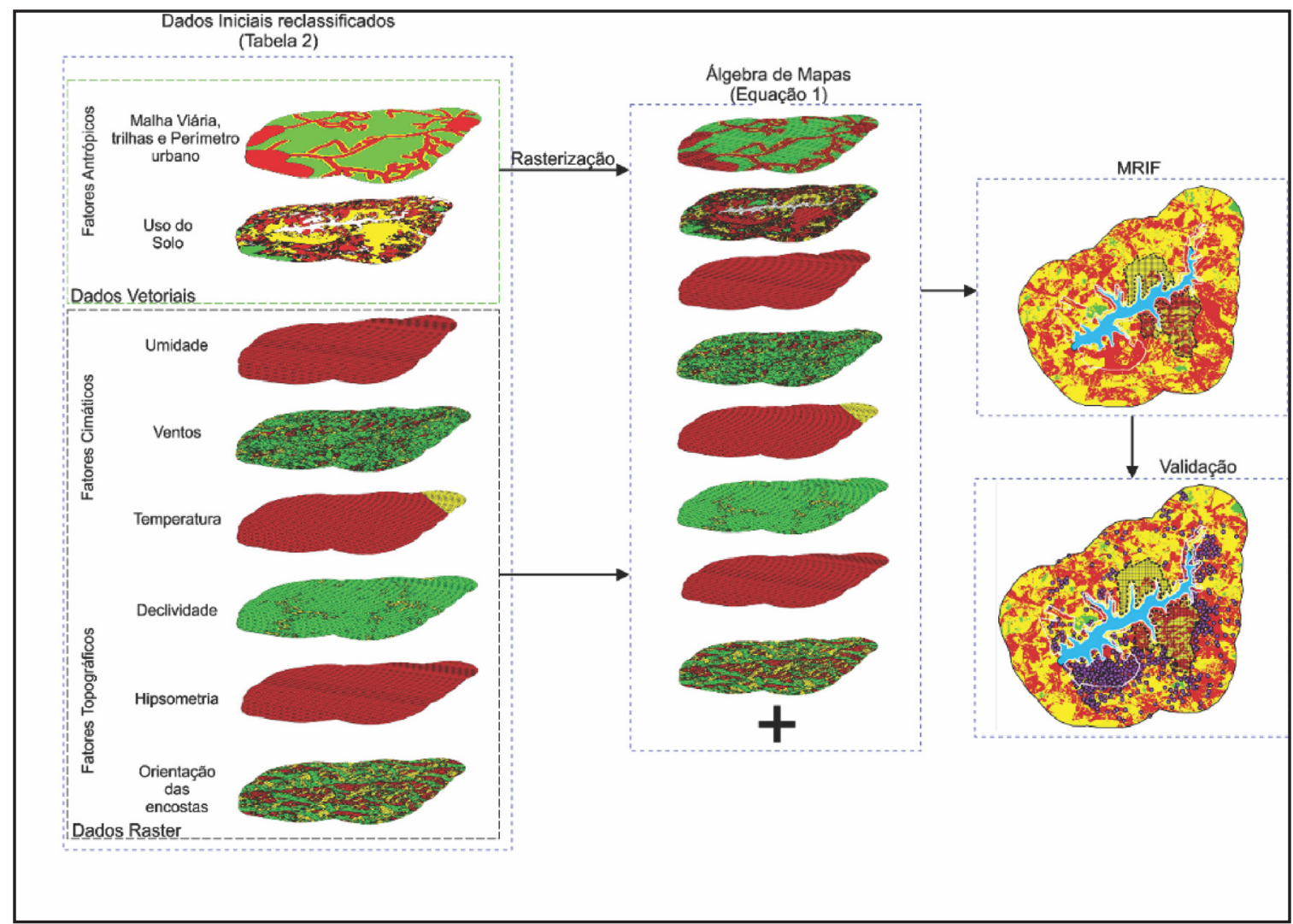

Fonte: Autores (2019)

\section{Validação do mapa de risco de incêndio florestal (MRIF)}

Produzir o MRIF não é suficiente, sendo necessária a validação dos resultados do modelo (TORRES et al., 2017). Contudo, Paz et al. (2011) apontam que a validação de modelos de risco de incêndio não é tarefa simples. Então, para a validação do MRIF gerado, foram utilizados 869 focos de calor observados entre os anos de 2005 a 2017, provenientes do sistema de detecção do Instituto Nacional de Pesquisas Espaciais/Centro de Previsão de Tempo e Estudos Climáticos (INPE/CPTEC, 2017) para sobreposição ao MRIF, não empregando outros tipos de técnicas específicas. 


\section{Definição de locais potenciais para instalação das torres de observação}

Definidas as áreas com maior risco de incêndio, procedeu-se com a escolha dos locais potenciais para implantação de torres de observação de incêndios. Para tanto, foram analisados os seguintes fatores, de acordo com os estudos de Venturi e Antunes (2007), Nogueira et al. (2002) e Assis et al. (2014):

- $\quad$ relevo (cotas de maior altitude);

- $\quad$ proximidade das estradas;

- $\quad$ proximidade com as regiões classificadas com risco moderado e alto;

- uso do solo.

Venturi (2006) aponta que o estudo do melhor local para a construção da torre deve levar em consideração as características do relevo, tendo em vista que as cotas de maior altitude possibilitam um raio superior de visão da área em questão. A proximidade das estradas foi considerada nas análises, pois, de acordo com Eugenio et al. (2016), não é interessante que os vigias se desloquem a pé a distâncias grandes. Portanto, considerou-se que a maior distância entra as estradas e as torres é de $600 \mathrm{~m}$.

A escolha dos locais potenciais para implantação das torres de observação buscou possibilitar uma maior cobertura das regiões classificadas com riscos moderado e alto para a ocorrência de incêndios. Em relação ao uso do solo, foram excluídas das análises as áreas com remanescentes de vegetação nativa, buscando assim evitar que para a instalação das torres fosse necessário desmatar a área.

Utilizando os critérios acima citados, procedeu-se com os testes que buscavam identificar os melhores locais potenciais de instalação das torres de observação, realizados de forma manual por meio da extensão View Shade Anlysis, disponível no software Qgis 2.18 (Qgis, 2017), gerando a área visível para cada torre. Para utilizar essa extensão é necessário informar, além do ponto de instalação, dados de entrada como altura da torre e raio de visão. Para tanto, adotou-se altura de 30 metros para as torres e raio de visão de $15 \mathrm{Km}$, valores considerados adequados e sugeridos por Nogueira et al. (2002) e Venture e Antunes (2007). Conforme apontado também por Soares e Batista (2003), cada torre pode cobrir uma área de visibilidade entre 8.000 e 15.000 ha, dependendo principalmente da topografia da região avaliada.

\section{Resultados e discussão}

A Figura 5a ilustra o MRIF do PEAMP, PEJol e área do entorno resultante da álgebra de mapas em ambiente SIG. A validação pode ser observada na Figura 5b, por meio da comparação das áreas de risco com os focos de incêndios detectados pelo INPE. Na Tabela 3, são apresentadas as classes de risco, as áreas e as suas respectivas porcentagens.

O risco "Nulo" é caracterizado somente pelo interior do corpo de água (RIBEIRO et al., 2008), ou seja, pelo reservatório de água João Leite. Em relação ao risco “Baixo”, pode-se destacar que ele se caracteriza principalmente pelas áreas em que o uso do solo foi classificado como solo exposto. Apesar de possuir risco nulo em relação à possibilidade de incêndio, o mesmo pode ser uma ameaça inicial ao fator de ignição, uma vez que permite ou indica uso antrópico (PEREIRA; DUTRA, 2017). Essa característica, associada aos parâmetros físicos (hipsometria) e climáticos (umidade e temperatura), possibilitou que essas áreas fossem classificadas com essa classe de risco.

Por sua vez o risco moderado está associado às áreas com cobertura vegetal remanescente e pastagens associadas a uma declividade predominantemente baixa (PEREIRA; DUTRA, 2017; ASSIS et al., 2014), bem como uma baixa incidência de ventos nas direções leste, oeste e nordeste. Pode-se observar a predominância dessa classe de risco dentro dos limites da parte norte do 
PEAMP, localizada acima do reservatório.

O risco alto se relaciona, principalmente, a dois fatores. O primeiro deles é antrópico, ou seja, proximidade de estradas, semelhante ao que foi encontrado por Lopes et al. (2018) em seus estudos. Uma possível explicação para esse fato está relacionada ao acesso facilitado nas proximidades das áreas de estudo, deposição de material combustível e maior pré-disposição de agentes dispersores humanos e não humanos (LOPES et al., 2018). Pereira et al. (2017) também identificaram que atividades antrópicas foram os principais elementos influenciadores nas classes de riscos.

Figura 5 - MRIF do PEAMP, PEJoL e área de entorno (a) e Validação do MRIF (b)

Figure 5 - PEAMP MRIF, PEJoL and surrounding Area (a) and MRIF validation (b)

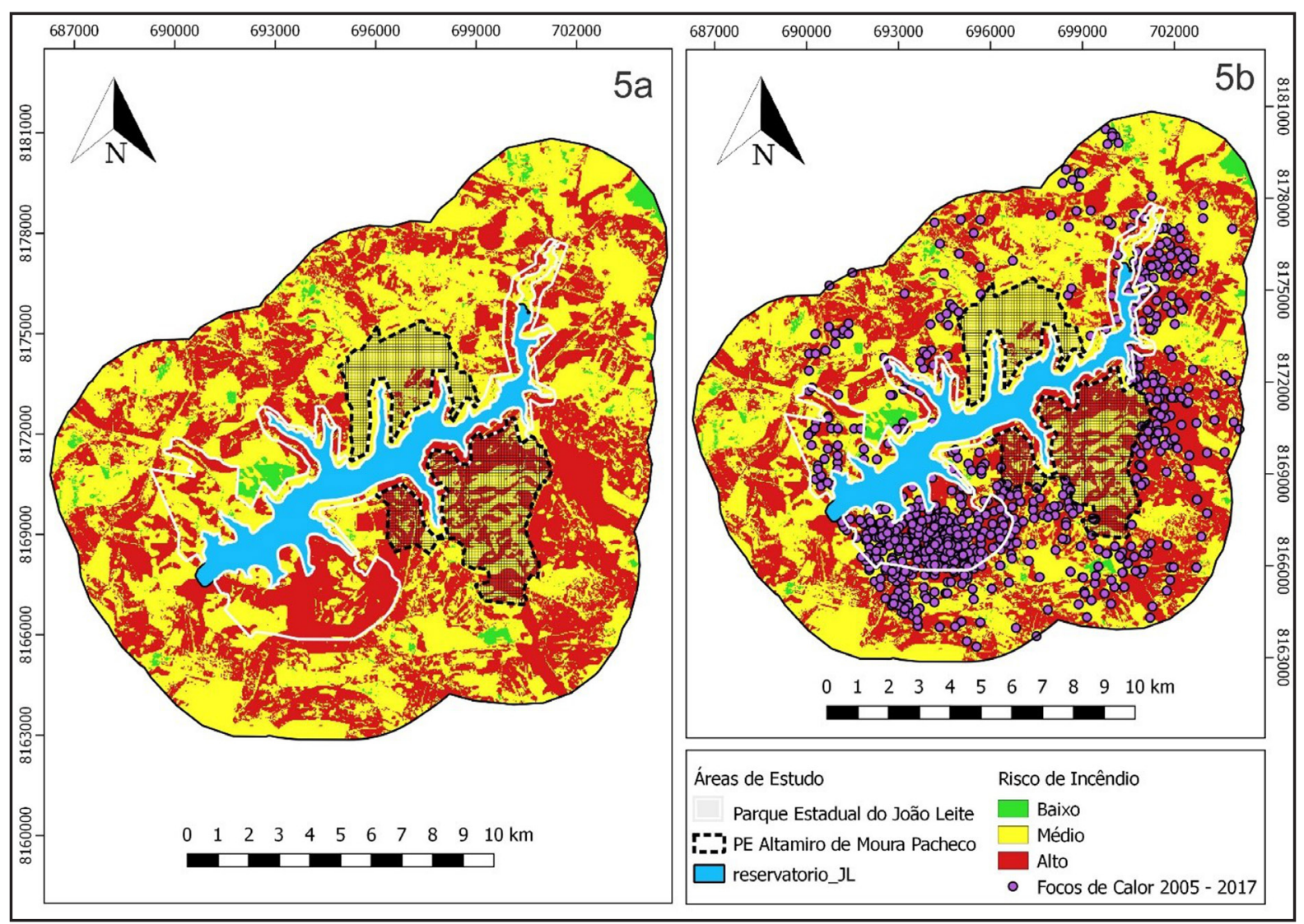

Fonte: Autores (2019)

O segundo fatorse refere à vegetação, do tipo Floresta Estacional Decidual (PROBIO, 2002), tendo em vista que nesse tipo de floresta mais de $50 \%$ de suas árvores perdem as folhas no período da seca (KILKA et al., 2014) aumentando, portanto, o material combustível disponível. Esse tipo de formação florestal pode ser observado dentro dos limites do PEJoL e também na parte sul do PEAMP, localizado abaixo do reservatório.

Buscando avaliar a qualidade do MRIF gerado, o mesmo foi comparado aos focos de incêndios registrados pelo INPE no período de 2005 a 2017 (INPE, 2017). Da Tabela 3, pode-se inferir que aproximadamente $60 \%$ dos focos de calor observados nas áreas de estudo incidiram sobre áreas classificadas como de risco "Alto". Associando as classes "Moderado" e "Alto", essa incidência chega a se aproximar de 100\%. Estudos de Pereira e Dutra (2017), Sharma et al. (2015) e Prudente (2010) foram validados com percentagens muito próximas dos valores obtidos nesta 
pesquisa. White et al. (2016) apontam ainda que, para percentuais iguais ou superiores a $60 \%$ do MRIF, o resultado pode ser considerado validado.

\section{Tabela 3 - Distribuição do risco e focos de incêndios}

Table 3 - Risk distribution and fire outbreaks

\begin{tabular}{lcccc}
\hline \multirow{2}{*}{ Classe de Risco } & \multicolumn{2}{c}{ Áreas } & \multicolumn{2}{c}{ Focos } \\
\cline { 2 - 5 } & $($ ha) & $(\%)$ & Quantidade & $(\%)$ \\
\hline Nulo & $1.423,36$ & 6,1 & 0 & 0,00 \\
Baixo & 433,98 & 1,8 & 5 & 0,58 \\
Moderado & $11.929,41$ & 50,7 & 337 & 38,78 \\
Alto & $9.724,66$ & 41,4 & 527 & 60,64 \\
\hline Total & $\mathbf{2 3 . 5 1 1 , 4 1}$ & $\mathbf{1 0 0}$ & $\mathbf{8 6 9}$ & $\mathbf{1 0 0 , 0 0}$ \\
\hline
\end{tabular}

Fonte: Autores (2019)

Para determinar os locais potenciais para instalação das torres de observação de incêndio florestal, inicialmente foram escolhidos 5 locais, levando em consideração fatores como: relevo, distância das estradas, proximidade das regiões classificadas com risco moderado e alto de incêndios e uso do solo (Figura 6).

Figura 6 - Locais potenciais para instalação das torres de observação de incêndios florestais

Figure 6 - Potential locations for the installation of forest fire observation towers

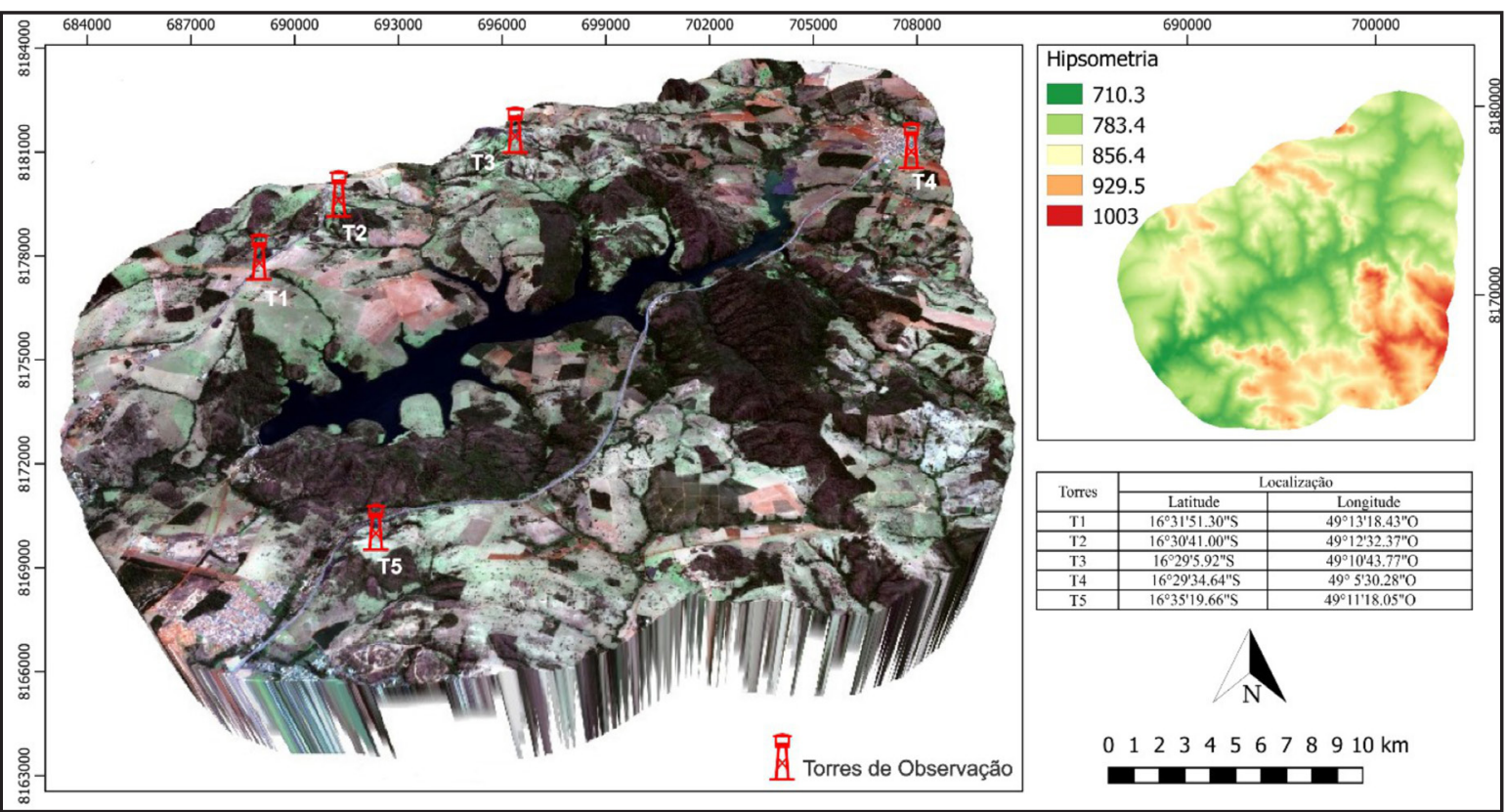

Fonte: Autores (2019) 
Posteriormente, fez-se a avaliação da visibilidade das torres, seja de forma individual ou buscando a melhor combinação (aos pares e aos trios) de sua implantação que possibilitassem maior monitoramento das áreas com relação aos focos de incêndios (Tabela 4).

\section{Tabela 4 - Porcentagem de área visualizada pelas torres}

Table 4 - Percentage of area viewed by towers

\begin{tabular}{lccccccc}
\hline \multirow{2}{*}{ Torres } & \multicolumn{5}{c}{ Classes de risco } & \multicolumn{3}{c}{ Áreas de estudo } \\
\cline { 2 - 7 } & Baixo (\%) & Médio (\%) & Alto (\%) & PEAMP (\%) & PEJoL (\%) & ZA $^{*}$ (\%) & Geral $^{* *}(\%)$ \\
\hline \multirow{2}{*}{ T1 } & 29,63 & 30,59 & 33,16 & 64,63 & 40,74 & 25,04 & 29,37 \\
T2 & 59,85 & 56,94 & 57,54 & 84,39 & 72,76 & 48,47 & 55,07 \\
T3 & 70,34 & 58,43 & 57,07 & 86,29 & 71,71 & 49,56 & 56,08 \\
T4 & 34,99 & 30,00 & 28,37 & 33,42 & 28,79 & 27,91 & 28,18 \\
T5 & 47,94 & 42,20 & 36,40 & 31,18 & 25,76 & 40,90 & 35,79 \\
T3 e T5 & 84,48 & 75,60 & 74,60 & 88,83 & 78,21 & 68,40 & 71,07 \\
T3, T4 e T5 & 92,30 & 82,98 & 81,30 & 93,19 & 83,04 & 75,73 & 78,12 \\
\hline
\end{tabular}

Fonte: Autores (2019)

Em que: $\left(^{*}\right)$ Zona de amortecimento; $\left.{ }^{(*}\right)$ Na visualização geral foi considerada a área pertencente ao reservatório de água.

Analisando individualmente as torres T2 e T3, elas apresentam maior visibilidade da área total, cobrindo áreas de 12.958,65 e 13.198,32 ha, respectivamente. Em relação às classes de risco, é possível observar que ambas possuem porcentagem de visualização próximas de $60 \%$. Quando analisadas as áreas de estudo de forma geral, a torre T3 é a que melhor proporciona o monitoramento do PEAMP e do PEJoL (Tabela 4).

Combinando-se a instalação de duas torres de observação, foi observado que as torres T3 e T5 implantadas possibilitam a maior área visualizada, ou seja, $16.724,34$ ha (71\% de todas as áreas de estudo). Simulando a possibilidade de implantação de três torres de observação de incêndios, a melhor combinação obtida foi entre as torres T3, T4 e T5 que, juntas, possibilitaram visualizar $18.384,03$ ha (78\% das áreas em estudo) (Tabela 4).

Soares e Batista (2003) apontam que uma cobertura de 70 a $80 \%$ de área visualizada é satisfatória. Com isso, seria necessária a instalação de duas torres de observação, T3 e T5. Contudo, é possível observar que a torre T3 sozinha possibilita boa cobertura de todas as áreas de estudo (Figura 7), principalmente quando analisadas as áreas visualizadas correspondentes às Unidades de Conservação (parques). Assis (2014) aponta que as demais áreas não visualizadas podem ser patrulhadas de outras formas (veículos motorizados, animais de montaria e/ou a pé). A Figura 7 ilustra os melhores cenários simulados para implantação das torres de observação de incêndios florestais (maior cobertura das áreas de estudo visualizadas). 


\section{Figura 7 - Áreas visualizadas pelas torres de observação de incêndio}

Figure 7 - Areas viewed by fire observation towers

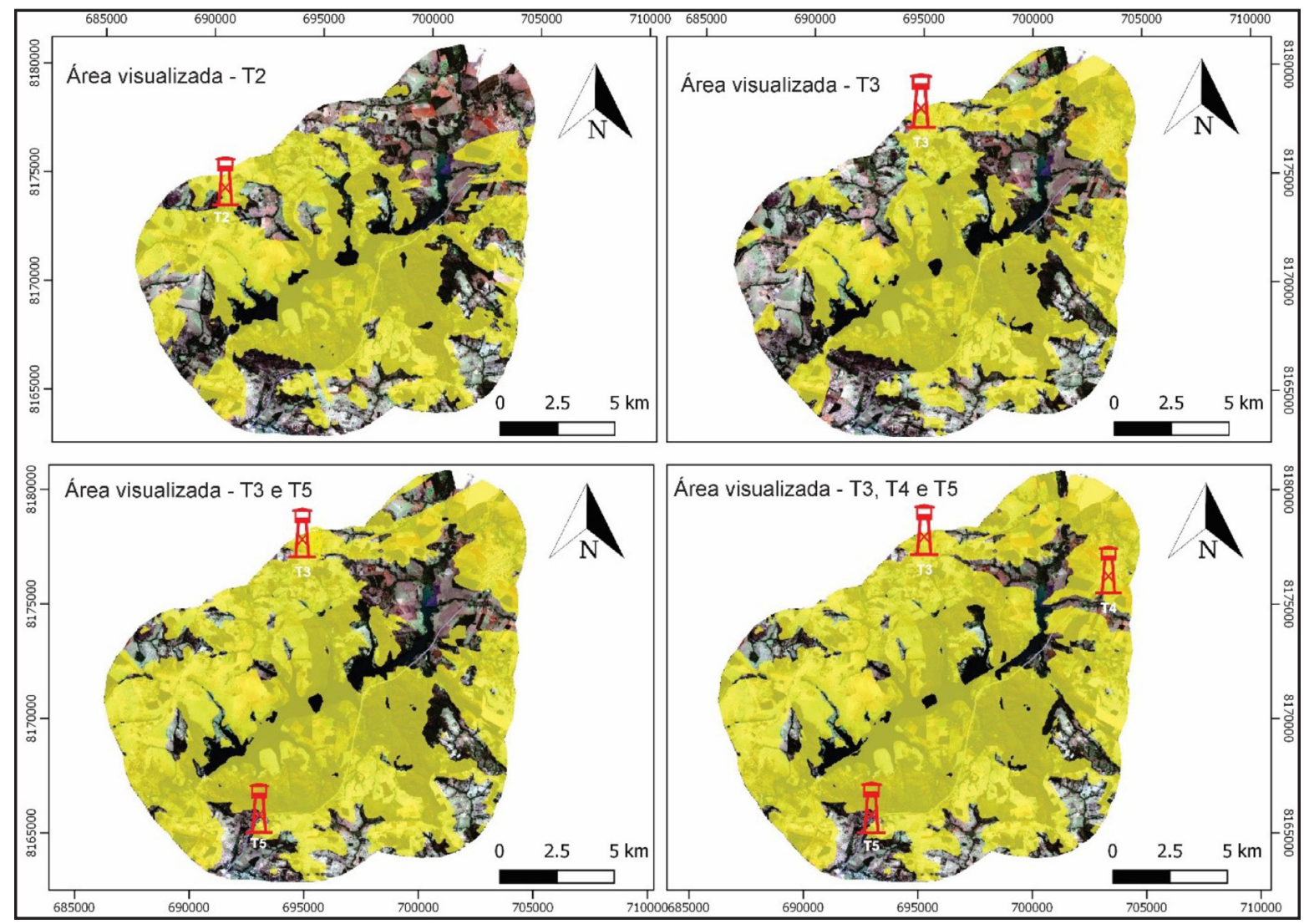

Fonte: Autores (2019)

\section{Conclusões}

Diante dos objetivos propostos e os resultados obtidos, conclui-se que o Sistema de InformaçõesGeográficas (SIG) é uma ferramenta que possibilita subsidiar elementos importantes para os planos de manejo, proteção e combate a incêndios florestais, principalmente para o bioma Cerrado, sendo gratuito para usuários e gestores ambientais.

A metodologia utilizada, principalmente a aplicação da Equação 1, mostrou-se adequada para a determinação das áreas com maior risco de incêndios florestais, tendo em vista que a sobreposição dos diversos parâmetros utilizados (climáticos e geográficos) possibilita uma visão global de suas influências, facilitando a tomada de decisão. Destaca-se, ainda, a possibilidade de aplicação da metodologia proposta para outras diferentes áreas de estudo. Contudo, alterações relativas a variáveis e parâmetros de entrada, pesos e classes de risco são possíveis e necessários,conforme as particularidades de cada caso.

Com relação aos resultados, o maior percentual de risco de incêndio identificado engloba as classes de risco "Moderado", ocupando aproximadamente $11.929,41$ ha (51\% das áreas de estudo), e risco "Alto", com 9.724,66 ha (41,4\% de toda área de estudo), justificados por proximidade de estradas (vias de acesso), uso do solo para pastagens e Floresta Decidual associadas a uma declividade predominantemente baixa. A validação do MRIF se mostrou satisfatória, considerando que $60 \%$ dos focos de calor indicados pelo INPE (2017) se localizam 
dentro das faixas de risco de incêndio "Alto" simuladas (mapeadas).

Em relação aos locais de implantação e quantidades de torres de observação de incêndio, destaca-se que nem sempre o ponto mais alto (maior cota) das áreas de estudo é o melhor local de implantação da torre, sendo necessária a avaliação de outros fatores, como: hipsometria, facilidade de acesso, não desmatamento da área, altura da torre e porcentagem de área visualizada. Assim, para as áreas de estudo avaliadas e considerando a influência dos fatores anteriormente descritos, o melhor local potencial para a instalação de torre de observação para prevenção de incêndios florestais, de forma individual, foi onde se encontra a torre T3 (Figura 7), caracterizada por visualizar $56,1 \%$ de todas as áreas de estudo e de 71,0 a $86,0 \%$ das áreas dos parques avaliados.

Optando-se por implantar duas torres de observação de incêndios, a melhor combinação encontrada para visualização de maior área foram os locais onde estão as torres T3 e T5 (71,07\% de todas as áreas de estudo e 78 a $89 \%$ dos parques avaliados). Esses percentuais são mais expressivos do que os encontrados para combinação de mais de duas torres. Para as áreas dos parques que não são possíveis de serem visualizadas pelas torres de observação de incêndios florestais, sugere-se o monitoramento por patrulhamento motorizado, montaria ou a pé.

Por fim, conclui-se que as ferramentas SIG mostraram-se eficazes para auxiliar na determinação dos melhores locais para instalação das torres de observação para prevenção de incêndios florestais nas áreas consideradas, auxiliando na preservação ambiental.

\section{Referências}

ALMEIDA, A. N.; ANDRADE, B. G.; SOARES, P. R.C; ANGELO, H. Segurança ambiental na estação ecológica de Águas Emendadas no Distrito Federal. Ciência Florestal, v. 28, n. 4, p. 13811393, 2018.

ASSIS, F. R. V.; DE MENDONÇA, I. F. C.; DA SILVA, J. E. R. LIMA, J. R. Uso de geotecnologias na locação espacial de torres para detecção de incêndios florestais no semiárido nordestino. Revista Floresta, Curitiba, v. 44, n. 1, p. 133-142, mar. 2014.

BARBOSA, M. R.; SEOANE, J. C. S.; BURATTO, M. G.; DIAS, L. S. O.; RAIVEL, J. P. C. MARTINS, F. L. Forest fire alert system: a GeoWeb GIS prioritization model considering land susceptibility and hotspots - a case study in the Carajás National Forest, Brazilian Amazon. International Journal of Geographical Information Science, London, v. 24, n. 6, p. 873-901, Apr, 2010.

BATISTA, A. C. Mapas de risco: uma alternativa para o planejamento de controle de incêndios florestais. Revista Floresta,Curitiba, v. 30, n. 1, 2, p. 45-54, 2000.

BRASIL. Resolução CONAMA № 428 de 17 de dezembro de 2010. Dispõe, no âmbito do licenciamento ambiental sobre a autorização do órgão responsável pela administração da Unidade de Conservação (UC), de que trata o $§ 3^{\circ}$ do artigo 36 da Lei no 9.985 de 18 de julho de 2000, bem como sobre a ciência do órgão responsável pela administração da UC no caso de licenciamento ambiental de empreendimentos não sujeitos a EIA-RIMA e dá outras providências. Diário Oficial da República Federativa do Brasil, Brasília, DF, 20 de dezembro de 2010.

CÂMARA, G.; SOUZA, R.C.M.; FREITAS, U.M. GARRIDO, J. SPRING: Integrating remote sensing and GIS by object-oriented data modelling. Computers \& graphics, [s.1], v. 20, n. 3, p.395403, jun. 1996.

CHUVieco, E. CONGALTON, R. G. Application of Remote Sensing and Geographic Information Systems to Forest Fire Hazard Mapping. Remote Sensoring of Enviromment, New York, v. 29, p. 147-159, 1989.

EUGENIO, F. C.; DOS SANTOS, A. R.; FIEDLER, N. C.; RIBEIRO, G. A.; DA SILVA, A. G.; JUVANHOL, R. S.; SCHETTINO, V. R.; MARCATTI, G. E.; DOMINGUES, G. F.; DOS SANTOS, G.M.A. D. A.; PEZZOPANE, J. E. M.; PEDRA, B. D.; BANHOS, A. MARTINS, L.D. GIS applied 
to location of fires detection towers in domain area of tropical forest. Science of the Total Environment, [s.l] v. 562, p. 542-549, ago. 2016.

FERRAZ, S. VETTORAZZI, C. Mapeamento de risco de incêndios florestais por meio de sistema de informação geográfica (SIG). Scientia Forestalis. São Paulo, v. 53, p. 39-48, jun. 1998.

FERREIRA, A. C.; ROCHA, L. C.; FIGUEIREDO, M. A.; CARDOZO, F. S.; GOMES, I. O impacto dos incêndios florestais na geodiversidade da Serra do Lenheiro - São João Del-Rei / MG - Brasil. Territorium, v.26, n.1, p. 87-96, 2019.

ITCO - Instituto De Desenvolvimento Tecnológico do Centro Oeste. Plano De Manejo APA João Leite. SEMARH / ITCO - Goiânia, 2007.

KILKA, R. V.; SCHIAVINI, I. MONTEIRO, G. A. Padrões florísticos em dois tipos de florestas estacionais no cerrado. Bioscience Journal, Uberlândia, v. 30, n. 3, ago. 2014.

LOPES, E. R. N.; SILVA, A. P. P.; PERUCHI, J. F.; LOURENÇO, R. W. Zoneamento de Risco de Incêndio e Queimadas no Município de Sorocaba - São Paulo. Revista do departamento de Geografia, v.36, p. 117-129, 2018.

MIRANDA, H. S.; BUSTAMANTE, M. M. C.; MIRANDA, A. C. The Fire Factor. In Oliveira, P. S. e Marquis, R. J., eds., The Cerrados of Brazil: ecologyand natural historyof a neotropical savanna, pp. 51-68. 2002.

NOGUEIRA, S. G.; RIBEIRO, A. G.; RIBEIRO, A. S. C. A. SILVA, P. E. Escolha de locais para instalação de torres de detecção de incêndio com auxílio do SIG. Revista Árvore, Viçosa, v. 26, n. 3, ago. 2002.

PAZ, S.; CARMEL, Y.; JAHSHAN, F. SHOSHANY, M. Post-fire analysis of pre-fire mapping of fire-risk: A recent case study from Mt. Carmel (Israel). Forest Ecologyand Management, Amsterdam, v. 262, n. 7, p. 1184-1188, 2011.

PEREIRA JUNIOR, A. C. Métodos de geoprocessamento na avaliação da susceptibilidade do cerrado ao fogo. 2002. 112p. Tese de Doutorado em Ecologia e Recursos Naturais - Programa de Pós-Graduação em Ecologia e Recursos Naturais, Universidade Federal de São Carlos (UFSCar), São Carlos, 2002.

PEREIRA, M. D. R.; COSTA, J. F.; CRISTO, S. S. V. Núcleo de educação, meio ambiente e desenvolvimento - NEMAD, v. 14, p. 99-115, 2017.

PEREIRA, R. S. DUTRA, G. C. Zoneamento de risco de incêndios florestais para o Parque Estadual Serra do Intendente-MG. In: SIMPÓSIO BRASILEIRO DE SENSORIAMENTO REMOTO, 18 (SBSR), Santos. Anais... São José dos Campos: INPE, 2017. p. 3546-3552. 2017.

PEZZOPANE, J. E. M.; OLIVEIRA NETO; S. N., VILELA, M. D. F. Risco de incêndios em função da característica do clima, relevo e cobertura do solo. Floresta e Ambiente, Rio de Janeiro, v. 8, n. 1, p. 161-165, jun. 2001.

PIMENTEL, L. C. G.; MARTON, E.; DA SILVA, M. S. JOURDAN, P. Caracterização do regime de vento em superfície na Região Metropolitana do Rio de Janeiro. Engenharia Sanitária e Ambiental, Rio de Janeiro, v. 19, n. 2, p. 121-132, ago. 2014.

PRUDENTE, T. D. Geotecnologias aplicadas ao mapeamento de risco de incêndio florestal no parque nacional da chapada dos veadeiros e área de entorno. 2010. 114p. Dissertação (Mestrado em Geografia) - Universidade Federal de Uberlândia, Uberlândia. 2010.

RIBEIRO, L. Percepção e uso do fogo por produtores rurais do município de Novo Mundo, Amazônia Mato-grossense. 2009. 146p. Tese (Doutorado em Ciências Florestais) - Programa de Pós-Graduação em Ciências Florestais, Setor de Ciências Agrarias, Universidade Federa do Paraná. Curitiba. 2009. 
RIBEIRO, L.; KOPROSKI, L. P.; STOLLE, L.; LINGNAU, C.; SOARES, R. V. BATISTA, A. C. 2008. Zoneamento de Riscos de incêndios florestais para a fazenda experimental do Canguiri, Pinhais (PR). Revista Floresta, Curitiba, v.38, n.3, set. 2008.

SALAS, J. CHUVIECO, E. Geographic information systems for wildland fire risk mapping. Wildfire, [s.l], v. 3, n. 2, p. 7-13, 1994.

SANTOS, F.A. DA CRUZ, M. L. Balanço hídrico climatológico da bacia hidrográfica do rio Piracuruca, nordeste do Brasil. IN: Anais... I Congresso Internacional da Diversidade do Semiárido. Campina Grande - PB, v. 1,2016.

SHARMA, N. R.; FERNANDES, P. J. F. POKHAREL, J. R. Methodological development for forest fire hazard mapping in Nepal. Revista Brasileira de Cartografia, Monte Carmelo, v. 3, n. 66/7, out. 2015.

SILVA, R. G. Manual de prevenção e combate aos incêndios florestais. Brasília: Instituto Brasileiro do Meio Ambiente e dos Recursos Naturais Renováveis, 1998, 80p., 1998.

SOARES, R. V. BATISTA, A. C. Controle de incêndios florestais: Combate aos incêndios florestais. Módulo 6. Brasília, DF: ABEAS, 2003.

TAVARES, M. F. D.; NAKAGOMI, B.; SOARES, V.; BOTEGA, L. C.; NERIS, V. P. A. Paisagens protegidas e incêndios florestais em Brasília: produção voluntária de informações geográficas e sistema de alerta. Territorium, n. 26 (I), p. 63-86, 2019.

TORRES, F. T. P.; ROQUE, M. P. B.; LIMA, G. S.; MARTINS, S. V. FARIA, A. L. L. Mapeamento do Risco de Incêndios Florestais Utilizando Técnicas de Geoprocessamento. Floresta Ambiente, Seropédica v. 24, abr. 2017.

TORRES, F. T. P.; TORRES, C. M. M. E.; LIMA, G. S.; MARTINS, S. V.; MENDES, A. E. O.; PADOVANI, M. T.; SIQUEIRA, R. G.; MOREIRA, G. F.; VALVERDE, S. R. Análise do perfil dos incêndios florestais no Parque Estadual da Serra do Brigadeiro e Entorno (MG). Ciência Florestal, v. 28, n. 3, p.1008-1021, jul-set., 2018.

VADREVU, K. P.; EATURU, A. BADARINATH, K. V. S. Fire risk evaluation using multicriteria analysis - a case study. Environmental Monitoring and Assessment, [s.l], v. 166, p.223-239, May, 2009.

VENTURI, N. L. Determinação de locais ótimos para implantação de torres de vigilância a incêndios florestais por meio de sistema de informações geográficas. 120p. Dissertação (Mestrado em Ciências Geodésicas) - Universidade Federal do Paraná, Curitiba. 2006.

VENTURI, N. L.; ANTUNES, A. F. B. Determinação de locais ótimos para implantação de torres de vigilância para detecção de incêndios florestais por meio de sistema de informações geográficas. Revista Floresta, Curitiba, v. 37, n. 2, ago. 2007.

WHITE, L. A. S.; WHITE, B. L. A.; RIBEIRO, G. T. Modelagem espacial de risco de incêndio florestal para o município de Inhambupe, Bahia, Brasil. Pesquisa Florestal Brasileira, Colombo, v. 36, n. 85 , p. 41-49, mar. 2016. 